\title{
Limiares culturais, balbucios interpretativos
}

\author{
Janine Resende Rocha*
}

\section{Resumo}

A partir dos conceitos Terceiro Espaço, de Homi Bhabha, e entre-lugar do discurso latino-americano, de Silviano Santiago, este trabalho pretende explorar como as atuais disposições da cultura relacionam-se com proposições interpretativas. Nessa relação, almeja-se observar como o conceito de "contemporâneo", defendido por Giorgio Agamben, pode contribuir para uma reflexão sobre os deslocamentos interpretativos da cultura por mirar os intervalos e as dissociações.

\section{Palavras-chave}

Terceiro Espaço. Entre-lugar. Contemporâneo. Cultura. Interpretação.

A caracterização de uma epistemologia pós-colonial, também demarcada como contemporânea, matiza o descrédito de teorias de verve universalizante, nas quais se prezam categorias rígidas. No que diz respeito à crítica cultural, esse horizonte de descrença é evidenciado na medida em que oposições binárias e cristalizações identitárias são desmentidas pelas assimetrias das configurações culturais em destaque no mundo globalizado. Ao imprimir mudanças no cenário do comparativismo literário, a globalização demanda metodologias que estejam atentas aos limiares, às línguas e à heterogeneidade cultural.

A partir dos conceitos Terceiro Espaço, de Homi Bhabha, e entre-lugar do discurso latino-americano, de Silviano Santiago, que têm a diferença cultural como orientação, este trabalho pretende explorar como as atuais disposições da cultura relacionam-se com proposições interpretativas. Nessa relação, almeja-se observar como o conceito de "contemporâneo", defendido por Giorgio Agamben, pode contribuir para uma reflexão sobre os deslocamentos interpretativos da cultura por mirar os intervalos e as dissociações.

\footnotetext{
* Doutoranda em Literatura Comparada pela Faculdade de Letras da UFMG. Desenvolve pesquisa sobre hermenêutica literária a partir das teorias de Mikhail Bakhtin e de Wolfgang Iser com bolsa da CAPES. E-mail: janine_rocha@hotmail.com.
} 


\section{0 "paradigma da guerra" e o século $X X$}

Ao longo das treze conferências - proferidas originalmente num seminário no Collège International de Philosophie no período de 1998 a 2001 - ora reunidas no livro intitulado $O$ século, Alain Badiou esquadrinha a trajetória do século XX. Nesse percurso, cuja marca é a de uma era de destruição, o filósofo ressalta a "paixão pelo real" (BADIOU, 2007, p. 58, grifos do autor) e o "paradigma da guerra" (BADIOU, 2007, p. 60; grifos do autor) como elementos do Zeitgeist do século, que perpassam as três definições elencadas por ele na palestra inaugural ao responder à questão "[q]ue é um século?" (BADIOU, 2007, p. 9).

A primeira definição cinge o "século soviético" (BADIOU, 2007, p. 10), que vai da Primeira Guerra Mundial até o encerramento da Guerra Fria. Para a segunda, encalacrada na raiz de um "século maldito" (BADIOU, 2007, p. 11), é determinante o massacre dos judeus na Segunda Guerra. Em decorrência dos "acontecimentos tão apocalípticos, tão apavorantes" (BADIOU, 2007, p. 11) que estão no enclave dessa definição, parece mais expressivo pautar-se pela radicalização do horror praticado em nome do comunismo stalinista e do nazismo do que pelas referências meramente temporais. A se ignorar o "furor mortal" (BADIOU, 2007, p. 13) dessa acepção, "[e]m última análise, o século XX seria o do triunfo do capitalismo e do mercado mundial. $O$ século expressaria a vitória da economia [...]. É o século liberal" (BADIOU, 2007, p. 13).

O método desenhado por Badiou para conceber o século XX consiste em valer-se de "máxima interioridade" (BADIOU, 2007, p. 17), em contraposição a dados ou números objetivos. Para tanto, impõe-se o caráter de relação entre o século e o significado que emerge de textos, de quadros e de demais manifestações artísticas. São analisados textos de Bertold Brecht, Fernando Pessoa, Ossip Mandelstam, Paul Celan, Saint-John Perse, entre outros. Nessas análises, repercutem as nuances de um século que, atrelado a uma problematização ontológica sobre a vida, persegue "uma mudança radical do que é o homem" (BADIOU, 2007, p. 23).

Por se afastar da "simples numeração empírica" (BADIOU, 2007, p. 17), a perspectiva metodológica projetada por Badiou parece apontar para um domínio historiográfico no qual se repudia um tipo de discurso - pretensamente oficial ou hegemônico -, preocupado em designar feitos retumbantes protagonizados por personagens notáveis. Nessa direção, sublinhamos com Jeanne Marie Gagnebin o declínio da narrativa tradicional postulado por Walter Benjamin, destacadamente nos ensaios "Experiência e pobreza", de 1933, e "O narrador", cuja escrita vai de 1928 a 1935. A partir do prisma das dissoluções dos metarrelatos, Gagnebin nos lembra como as formulações benjaminianas são decisivas para se pensar a genealogia das literaturas moderna e contemporânea, bem como da historiografia e da filosofia atuais (GAGNEBIN, 2006, p. 49). Essa concepção de um discurso fragmentário ou entrecortado - e, portanto, avesso a um télos - condecora também a expressão dos testemunhos, essas narrativas "simultaneamente impossíveis e necessárias" (GAGNEBIN, 2006, p. 49) que captam um outro modo de falar do passado, indiferente ao método monológico da historiografia tradicional. 
Na descrição feita por Gagnebin, o narrador benjaminiano

\begin{abstract}
seria a figura do trapeiro [...], do catador de sucata e de lixo, esta personagem das grandes cidades modernas que recolhe os cacos, os restos, os detritos, movido pela pobreza, certamente, mas também pelo desejo de não deixar nada se perder [...].

Esse narrador sucateiro (o historiador também é um Lumpensammler) não tem por alvo recolher os grandes feitos. Deve muito mais apanhar tudo aquilo que é deixado de lado como algo que não tem significação, algo que parece não ter importância nem sentido, algo com que a história oficial não sabe o que fazer. $O$ que são esses elementos de sobra do discurso histórico? A resposta de Benjamin é dupla. Em primeiro lugar, o sofrimento indizível que a Segunda Guerra Mundial levaria ao auge, na crueldade dos campos de concentração [...]. Em segundo lugar, aquilo que não tem nome, aqueles que não têm nome, o anônimo, aquilo que não deixa nenhum rastro, aquilo que foi tão bem apagado que mesmo a memória de sua existência não subsiste - aqueles que desapareceram tão por completo que ninguém lembra de seus nomes. Ou ainda: o narrador e o historiador deveriam transmitir o que a tradição, oficial ou dominante, justamente não recorda. Essa tarefa paradoxal consiste, então, na transmissão do inenarrável, numa fidelidade ao passado e aos mortos, mesmo - principalmente - quando não conhecemos nem seu nome nem seu sentido. (GAGNEBIN, 2006, p. 53-54).
\end{abstract}

O narrador benjaminiano é, assim, emblemático das "grandes dificuldades que pesam sobre a possibilidade da narração, sobre a possibilidade da experiência comum, enfim, sobre a possibilidade da transmissão e do lembrar." (GAGNEBIN, 2006, p. 54).

Na contemporaneidade, essas "dificuldades" são constantemente identificadas nos mapeamentos teóricos, o que, ao menos indiretamente, mostra possíveis reverberações da Shoah na prática das humanidades ${ }^{1}$, como uma inflexão impressa no logos, na cultura e na arte - agenciada a partir do sofrimento pavoroso infligido pelo homem a seus semelhantes num "dos poucos episódios históricomundiais comparáveis em barbárie com a escravidão moderna" (HALL, 2011, p. 28). O vínculo entre o pensamento teórico e os atos de extermínio da Segunda Guerra impulsiona, por exemplo, a tensão que polariza a obra de Giorgio Agamben.

Junto à figura do homo sacer, que tem uma força gravitacional no seu arcabouço especulativo, Agamben denuncia o espaço da política como uma zona de indistinção, onde, ao contrário do que seria de se imaginar, o estado de natureza permanece em vigor, verificado naquela capacidade de se infligir sofrimento ${ }^{2}$. A vida simples natural, que tem seu lugar na casa, ou a vida social, que tem seu lugar na cidade, por pressuposto, não são condizentes com o poder do soberano, e sim a vida nua ou sacra, que tem seu lugar no campo e que torna indiferentes os estados de natureza e de cultura. A dimensão jurídico-política disposta pelo homo sacer inviabiliza a cidade como o espaço do estado de cultura, onde está o direito. O campo de concentração é, então, transformado no espaço da política moderna.

O homo sacer protagoniza a significação política do estado de exceção, condicionado pela aporia decorrente da interrupção, total ou parcial, do ordenamento jurídico e da criação de uma zona de anomia amparada na letra constitucional. Paradoxalmente, a lei constitucional é aplicada na medida em que é desaplicada. 0

\footnotetext{
${ }^{1}$ Nesse sentido, ver o ensaio "Após Auschwitz", de Jeanne Marie Gagnebin (2006, p. 59-81).

${ }^{2}$ Ver Homo sacer: o poder soberano e a vida nua I, de Giorgio Agamben (2007).
} 
trâmite conceitual empenhado por Agamben vai não apenas ao encontro dos procedimentos excepcionais, mas do que seria, a partir dessa caracterização excepcional, o imperativo da política moderna como um todo, uma vez que, para o filósofo, "o estado de exceção tende cada vez mais a se apresentar como o paradigma de governo dominante na política contemporânea" (AGAMBEN, 2004, p. 13), tendo atingido hoje "seu máximo desdobramento planetário" (AGAMBEN, 2004, p. 131).

Vale lembrar que Benjamin - referência das mais caras a Agamben -, antes mesmo do acachapante horror praticado pelo nazismo, propôs nas teses sobre o conceito da história que "[a] tradição dos oprimidos nos ensina que o 'estado de exceção' em que vivemos é na verdade a regra geral" (BENJAMIN, 1994, p. 226). Ao subscrever nessas teses um ponto de vista historiográfico que destoe daquele focado nos vencedores ou dominadores, Benjamin tipifica o historiador-trapeiro, o qual, além de articular o passado como uma reminiscência, isto é, como a imagem de um relâmpago fugaz, recolhe os fragmentos, os restos, os corpos abatidos - resíduos a que Benjamin denomina cultura:

\begin{abstract}
Todos os que até hoje venceram participam do cortejo triunfal, em que os dominadores de hoje espezinham os corpos dos que estão prostrados no chão. Os despojos são carregados no cortejo, como de praxe. Esses despojos são o que chamamos bens culturais. [...] Nunca houve um monumento da cultura que não fosse também um monumento da barbárie. E, assim como a cultura não é isenta de barbárie, não o é, tampouco, o processo de transmissão da cultura. (BENJAMIN, 1994, p. 225).
\end{abstract}

Possivelmente influenciado pela leitura das teses "Sobre o conceito de história", Theodor Adorno radicalizou esse conceito de cultura na sua Dialética negativa: "Toda cultura após Auschwitz, inclusive a crítica urgente a ela, é lixo" (ADORNO apud GAGNEBIN' 2006, p. 73). Ao comentar essa definição no ensaio "Após Auschwitz", Gagnebin observa como a expectativa de que a cultura, "na sua pretensão de formar uma esfera superior que exprima a nobreza humana, revela-se um engodo, um compromisso covarde, um 'documento da barbárie', como disse Walter Benjamin" (GAGNEBIN' 2006, p. 72). Assim, a dedução do "lixo" de que fala Adorno, no entendimento de Gagnebin, "não é somente o que fede e apodrece, mas antes de mais nada é o que sobra, o de que não se precisa, o que pode ser jogado fora porque não possui plena existência independente" (GAGNEBIN' 2006, p. 73). Poderíamos completar dizendo: é o extraviado ou, a se levar em conta a visibilidade que o lixo adquire na sociedade atual, é o incômodo - em razão do acúmulo, do mau cheiro e da poluição dele resultante. No entanto, pode ser o reciclável e, por isso, o que retorna.

O efeito de retorno, o adiamento do que seria descartável - isto é, a chance de se ver o débil vicejar, de se ater à potência de uma sobrevida - marca a assinatura do contemporâneo de Agamben no ensaio "O que é o contemporâneo?", proferido originalmente como palestra em 2006. A contemporaneidade, no sentido específico atribuído a ela por Agamben na esteira de Benjamin, instaura um tempo "cronologicamente indeterminado" (AGAMBEN, 2009, p. 71), flexionado pelo residual, pelo que, caracterizado como origem, não pode ser vivido. O presente é 
a parte de não-vivido em todo vivido, e aquilo que impede o acesso ao presente é precisamente a massa daquilo que, por alguma razão (o seu caráter traumático, a sua extrema proximidade), neste não conseguimos viver. A atenção dirigida a esse não-vivido é a vida do contemporâneo. (AGAMBEN, 2009, p. 70).

O contemporâneo, por pressupor a cesura do tempo, a descontinuidade - ou, na imagem benjaminiana, "um tempo saturado de 'agoras"" (BENJAMIN, 1994, p. 229) -, singulariza um distanciamento, que requer, portanto, a condição de um deslocar-se. Para ser contemporâneo, é preciso exercitar um descentramento e voltar-se para o "outro" - que pode estar subreptício em nós mesmos, como realça o unheimlich freudiano.

Em razão desse movimento, aquele que é contemporâneo defende-se da normalização do pensamento e das narrativas. Por isso, é capaz de dissociar, por exemplo, instâncias de transcendência - como nação, raça, cultura, Ocidente - que referenciam e oprimem grandes coletivos. É capaz de criar sua própria filia, da maneira subversiva como Jorge Luis Borges o faz em "Kafka e seus precursores" ao alertar que: "cada escritor cria seus precursores. Seu trabalho modifica nossa concepção do passado, como há de modificar o futuro" (BORGES, 1999, p. 98; grifo do autor). Mecanismo de desapropriação semelhante ao empregado por Vicent Degraël pesquisador de literatura personagem do conto "A viagem de inverno", de Georges Perec -, ao se dar conta, em 1939, de que toda uma tradição de poetas havia plagiado certo livro, borgeneamente inacabável, de Hugo Vernier, um poeta prodigioso, porém, absolutamente desconhecido:

\begin{abstract}
Vernier havia "citado" um verso de Mallarmé com dois anos de antecipação, plagiado Verlaine dez anos antes de suas "Pequenas árias esquecidas", escrito versos de Gustave Kahn cerca de um quarto de século antes dele! Isso queria dizer que Lautréamont, Germain Nouveau, Rimabaud, Corbière e outros mais não passavam de copistas de um poeta genial e desconhecido que, numa obra única, soubera recolher a própria substância de que se nutririam em seguida três ou quatro gerações de autores! (PEREC, 2005, p. 79).
\end{abstract}

A pulsação do contemporâneo agambeniano não inibe o diálogo com o passado - por compreender, na afinação nietzschiana do conceito, o intempestivo - e não é autoevidente, já que, paradoxalmente, "[o] nosso tempo, o presente, não é, de fato, apenas o mais distante: [ele] não pode em nenhum caso nos alcançar [...]." (AGAMBEN, 2009, p. 65). O contemporâneo implica a percepção de obscuridades no presente e do jogo de sombras com o passado mediante um processo de desleitura, que estimula novas relações:

dividindo e interpolando o tempo, está à altura de transformá-lo e de colocá-lo em relação com os outros tempos, de nele ler de modo inédito a história, de "citá-la" segundo uma necessidade que não provém de maneira nenhuma do seu arbítrio, mas de uma exigência à qual ele não pode responder (AGAMBEN, 2009, p. 72; grifos nossos). 
Nesse processo, Agamben indica uma diretriz similar à de Alain Badiou no seu estudo sobre o século XX, pois, para tornar legíveis os vestígios do "não-vivido", devese "ser contemporâneo não apenas do nosso século e do 'agora', mas também das suas figuras nos textos e nos documentos do passado." (AGAMBEN, 2009, p. 73).

\section{O entre-lugar e a tarefa da interpretação}

O surgimento de uma episteme, que, à maneira agambeniana de pensar o contemporâneo, deriva do sofrimento indizível levado a cabo na Segunda Guerra ${ }^{3}$, instiga, como já observado, a uma reflexão sobre a cultura. Na definição dessa conjuntura sobressai a tarefa rememorativa do historiador-trapeiro, pois essa episteme não nos permitiria falar da cultura como sendo uma instância de produção de referências coletivas - que se tornam cada vez mais distantes e imaginárias na medida em que assumem proporções macroscópicas -, e sim como uma política configurada a partir da relação que se tem com o "outro." Fundamentalmente, essa configuração atém-se ao intraduzível ou incompreensível, isto é, ao residual que se impõe quando nos colocamos no lugar do "outro."

O estudo da cultura hoje deve estar atento à força subversiva da espacialidade do meio, do entre-lugar, cuja topografia salienta atributos como dispersão, estranhamento, desestabilização, que comprometem indicadores de autenticidade, pureza ou unicidade. O rearranjo advindo desse descentramento pode ser corroborado pela experiência da diáspora. A diáspora ilumina, conforme Stuart Hall dispôs ao examinar o destino migratório do povo caribenho, a complexidade das identidades, que se tornam múltiplas, especialmente na atual fase transnacional da globalização:

O conceito fechado de diáspora se apoia sobre uma concepção binária de diferença. Está fundado sobre a construção de uma fronteira de exclusão e depende da construção de um "Outro" e de uma oposição rígida entre o dentro e o fora. Porém, as configurações sincretizadas da identidade cultural caribenha requerem a noção derridiana de différance - uma diferença que não funciona através de binarismos, fronteiras veladas que não separam finalmente, mas são também places de passage, e significados que são posicionais e relacionais, sempre em deslize ao longo de um espectro sem começo nem fim. A diferença, sabemos, é essencial ao significado, e o significado é crucial à cultura. Mas num movimento profundamente contraintuitivo, a linguística moderna pós-saussuriana insiste que o significado não pode ser fixado definitivamente. Sempre há o "deslize" inevitável do significado na semiose aberta de uma cultura, enquanto aquilo que parece fixo continua a ser dialogicamente reapropriado. A fantasia de um significado final continua assombrada pela "falta" ou "excesso", mas nunca é apreensível na plenitude de sua presença a si mesma. (HALL, 2011, p. 33).

\footnotetext{
${ }^{3}$ Caracterizando essa episteme, Márcio Seligmann-Silva afirma: "A memória da Shoah assume agora um papel central na estruturação de um modelo epistemológico no qual o 'saber' é visto como uma reescritura aberta, nunca completa e total. Como reescritura infinita de textos e do passado, justamente porque nessa memória o outro/"resto" reivindica a sua voz de um modo nunca antes experimentado. Enquanto evento traumático, a Shoa está servindo de base para se estabelecer e pensar uma memória coletiva que também deve atuar no movimento de resistência à homogeneização das diferenças passadas e presentes". (SELIGMANN-SILVA, 2005, p. 212, grifos do autor).
} 
Sublinhado por Hall, o caráter dispersivo da diáspora reflete com precisão o ponto acentuado neste trabalho: como o binarismo - diretor de modelos culturais pautados pelo essencialismo - é subvertido por meio do residual, que, gerado no contato entre culturas diferentes, inviabiliza a sedimentação do significado, transposto num jogo permanente.

Nesse contexto, o encontro entre culturas diferentes não incorre num nivelamento, resistência que dificulta, na cultura pós-colonial, a efetivação do poder dos dominadores. $O$ ingresso na zona de contato intercultural, metaforizada pelo entre-lugar, exemplifica a vertiginosa "relação com os outros tempos" mencionada por Agamben na sua teorização sobre o que é o contemporâneo. Tanto o ingresso real nessa zona como a compreensão, explicação e significação da cultura do "outro" frisam relações de contraste e de comparação que podem ser verificadas, em hipótese, na marcação do tempo. Cada cultura articula um tempo, perturbado mediante a intervenção de uma cultura distinta, numa conjugação que pronuncia um modo novo de se ler a história. De acordo com a lógica da différance, norteadora da reflexão de Hall, essas relações podem ainda ser reformuladas nos seguintes termos: "Filosoficamente, a lógica da différance significa que o significado/identidade de cada conceito é constituído(a) em relação a todos aos demais conceitos do sistema em cujos termos ele significa" (HALL, 2011, p. 81). Assim, para que seja certificada, a diferença particular de um grupo ou comunidade deve ser determinada perante um contexto amplo e pelo "outro."

Como mencionado, o entre-lugar é, por excelência, a imagem que registra o encontro entre diferentes culturas. Operador do pensamento de Silviano Santiago, o termo foi apresentado inicialmente por ele no ensaio "O entre-lugar do discurso latinoamericano", de 1971, antes até das alterações de alcance planetário que, sobretudo a partir da década de 1970, passaram a consagrar o fenômeno da globalização e os mercados capitalistas. $\mathrm{O}$ ensaio foi escrito com o propósito de contextualizar o lugar do discurso literário latino-americano perante o europeu. Nessa discussão, mediada pela teoria de Jacques Derrida, Santiago evidencia o potencial recriativo de uma cultura, catalisado, no caso descrito por ele, pela insubordinação do colonizado diante da cultura europeia:

O renascimento colonialista engendra por sua vez uma nova sociedade, a dos mestiços, cuja principal característica é o fato de que a noção de unidade sofre reviravolta, é contaminada em favor de uma mistura sutil e complexa entre o elemento europeu e o elemento autóctone - uma espécie de infiltração progressiva efetuada pelo pensamento selvagem, ou seja, abertura do único caminho possível que poderia levar à descolonização. (SANTIAGO, 2000, p. 15, grifos do autor).

Por desativar invariavelmente a unidade e a pureza, o rearranjo viabilizado por meio de uma assimilação a contrapelo - uma assimilação antropofágica, portanto fundamenta a "maior contribuição da América Latina para a cultura ocidental" (SANTIAGO, 2000, p. 16). Para os escritores, essa assimilação, que transgride os modelos europeus, requer, como resultado, um novo texto, uma transcriação, pela qual "o trabalho do escritor em lugar de ser comparado ao de uma tradução literal, 
propõe-se antes como uma espécie de tradução global, de pastiche, de paródia, de digressão" (SANTIAGO, 2000, p. 21). O uso que o escritor faz do texto de outrem, expresso numa língua estrangeira, compreende a condição de reescritura que deve ser verificada também nos limiares culturais.

Aplicada à cultura, a metáfora da textualidade - que valoriza a "semiose aberta de uma cultura", priorizada por Hall ao estudar a diáspora - agencia uma reescritura indefinida, que desfaz a possibilidade mimética ou de cópia da cultura dominante. Esse componente escritural imprime a rasura - sempre refeita - da origem, que descaracteriza, por conseguinte, a qualidade original de uma cultura e de um significado. O deslocamento operacionalizado pela reescritura impede a construção estanque ou homogeneizada do significado, incorporado, numa contradição aparente, mediante um adiamento constante. Sustentando ainda a metáfora da textualidade, é preciso observar, junto com Santiago em "Análise e interpretação" - ensaio escrito por volta de 1975 que deve ser entendido de forma complementar ao citado anteriormente -, que esse adiamento promove intervalos e aberturas na interpretação. A tarefa da interpretação, de linhagem foucaultiana, é assim compreendida pelo crítico brasileiro:

\begin{abstract}
É ela uma tarefa infinita, porque nunca se pode completar, mas não se completa porque não há nada para se interpretar, isto é, nada de primeiro para ser interpretado. Tudo já é interpretação. Assim sendo, a interpretação sempre se volta sobre si mesma, criando este movimento de circularidade que será então definidor do movimento do conhecimento humano. (SANTIAGO, 2000, p. 215).
\end{abstract}

Essa "tarefa infinita" corrobora a problematização da origem de uma cultura, pois a cultura que seria a original já é, por si mesma, a interpretação de outras culturas.

No livro O local da cultura, de 1994, Homi K. Bhabha enfatiza o vigor do prefixo que designa a posição intermediária: "é o 'inter' - o fio cortante da tradução e da negociação, o entre-lugar - que carrega o fardo do significado da cultura" (BHABHA, 2010, p. 69, grifos do autor). O entre-lugar negocia a diferença cultural, a diferença que não tabela o "outro" como exótico nem pode ser coibida pela tolerância. Bhabha é taxativo ao esclarecer que o processo incutido na diferença cultural não pode ser confundido com a diversidade cultural. Embora escrevam significantes parecidos, guardam acepções bem distintas:

a diferença cultural é um processo de significação através do qual afirmações da cultura ou sobre a cultura diferenciam, discriminam e autorizam a produção de campos de força, referência, aplicabilidade e capacidade. A diversidade cultural é reconhecimento de conteúdos e costumes culturais pré-dados; mantida em um enquadramento temporal relativista, ela dá origem a noções liberais de multiculturalismo, de intercâmbio cultural ou da cultura da humanidade. A diversidade cultural é também a representação de uma retórica radical da separação de culturas totalizadas que existem intocadas pela intertextualidade de seus locais históricos, protegidas na utopia de uma memória mítica de uma identidade coletiva única (BHABHA, 2010, p. 63; grifos do autor). 
A diferença cultural demanda o reconhecido do potencial recriativo de uma cultura, já a diversidade reproduz uma lógica binária, uma vez que estabiliza as referências.

A partir da leitura do romance Mongólia, de Bernardo Carvalho, é possível constatar como a diversidade cultural não favorece uma perspectiva relacional. No livro, o encontro entre culturas diferentes gera uma instabilidade, que não se confunde, contudo, com o deslizamento semiótico do qual fala Hall. Essa instabilidade ocorre quando, sob a ótica de valores cristalizados, reconhece-se na cultura do "outro" o anômalo - ou, num termo menos impactante, o excêntrico. É sob a chave da incompatibilidade que um brasileiro, identificado sugestivamente como "Ocidental", encontra vários nômades mongóis ao longo do deserto de Gobi, nos confins da Mongólia. Em missão diplomática, o brasileiro vai até esse país para tentar localizar o filho - então desaparecido - de um poderoso empresário.

Na narrativa de Carvalho, o estranhamento recíproco - que é uma constante no contato entre os personagens das duas nacionalidades - impede a compreensão do "outro":

O Ocidental logo receberia a resposta, ao ser confrontado com o espanto e a timidez de nômades que o evitavam ou o observavam como a um animal exótico. $O$ desaparecido podia ter passado por ali, ou não, mas certamente não encontrara as mesmas pessoas. E até o final da viagem não lhe faltariam ocasiões para se acostumar com os bêbados e os curiosos que nunca tinham visto um estrangeiro e o devoravam com os olhos ao vê-lo pela primeira vez (CARVALHO, 2003, p. 118; grifos nossos).

Nessa passagem, a comparação pejorativa é direcionada ao diplomata também visto em outro momento "como se fosse um extraterrestre" (CARVALHO, 2003, p. 53) -, já nesta, escrita pelo jovem desaparecido em seu diário, são os mongóis os desfavorecidos: "Os homens [os nômades] estão reunidos numa das tendas, jogando cartas. [...]. Somos solenemente ignorados. Devem estar cheios dos estrangeiros curiosos que vêm vê-los como se fossem animais em vias de extinção" (CARVALHO, 2003, p. 43, grifos nossos).

O encontro entre culturas diferentes nos confins da Mongólia não desencadeou as desleituras condicionadas pelo Terceiro Espaço, distinguido por Bhabha ao articular a diferença cultural. Para ele:

É o Terceiro Espaço, que embora em si irrepresentável, constitui as condições discursivas da enunciação que garantem que o significado e os símbolos da cultura não tenham unidade ou fixidez primordial e que até os mesmos signos possam ser apropriados, traduzidos, re-historicizados e lidos de outro modo. (BHABHA, 2010, p. 67-68).

No romance, o confronto com o estrangeiro mostra como a diversidade cultural pode render impressões estereotipadas - ou caricaturas a serem reproduzidas em cartões-postais -, especialmente quando a cultura do "outro" suscita um agudo efeito de estranhamento. 
O "balbucio teórico", expressão da qual nos valemos para compor o título deste trabalho, remete à categoria proposta por Hugo Achugar ${ }^{4}$ para mobilizar o discurso teórico latino-americano e o seu histórico de incompreensão perante os europeus e os norte-americanos. A expressão decorre tanto do rebaixamento imputado a esse discurso como do fato de o mesmo revolver resíduos intraduzíveis. No entanto, é pela afirmatividade da pronúncia disjuntiva do balbucio que tal discurso revela a sua candência. Podemos dizer que as "condições discursivas da enunciação" previstas pelo Terceiro Espaço são determinantes para a língua do balbucio. Essa língua deixa de acolher os termos essencializadores - que motivam as imagens estéreis ${ }^{5}$ daquele que é estrangeiro, conforme talhadas pelos personagens do romance de Carvalho - para irradiar a compreensão eventualmente esboçada quando tentamos interpretar o "outro", ato criativo pelo qual se tateia o estranho, ou seja, o que é de fora.

\section{Referências}

ACHUGAR, Hugo. Planetas sem boca: escritos efêmeros sobre arte, cultura e literatura. Trad. Lyslei Nascimento. Belo Horizonte: Ed. UFMG, 2006.

AGAMBEN, Giorgio. Estado de exceção. Trad. Iraci D. Poleti. São Paulo: Boitempo, 2004.

Homo sacer: o poder soberano e a vida nua I. Trad. Henrique Burigo. Belo Horizonte: Ed. UFMG, 2007.

O que é o contemporâneo? Trad. Vinícius Nicastro Honesko. In: $\mathbf{0}$

que é o contemporâneo? e outros ensaios. Chapecó: Argos, 2009. p. 55-73.

BADIOU, Alain. O século. Trad. Carlos Felício da Silveira. Aparecida: Ideias \& Letras, 2007.

BENJAMIN, Walter. Sobre o conceito da história. In: Magia e técnica, arte e política: ensaios sobre literatura e história da cultura. Trad. Sérgio Paulo Rouanet. 7. ed. São Paulo: Brasiliense, 1994. (Obras escolhidas; v. 1) p. 222-232.

BHABHA, Homi K. O local da cultura. Trad. Myriam Ávila, Eliana Lourenço de Lima Reis, Gláucia Renate Gonçalves. Belo Horizonte: Ed. UFMG, 2010.

BORGES, Jorge Luis. Kafka e seus precursores. In: Obras completas de

Jorge Luis Borges. São Paulo: Globo, 1999. v. 2. p. 96-98.

CARVALHO, Bernardo. Mongólia: romance. São Paulo: Companhia das Letras, 2003.

GAGNEBIN, Jeanne Marie. "Após Auschwitz". In: Lembrar escrever esquecer. São Paulo: Ed.34, 2006. p. 59-81. Memória, história, testemunho. In: Lembrar escrever esquecer. São Paulo: Ed.34, 2006. p. 49-57.

\footnotetext{
${ }^{4}$ Ver especialmente a primeira parte do livro Planetas sem boca, que reúne ensaios de sua autoria (ACHUGAR, 2006).

${ }^{5}$ Vale lembrar que "estéreo" compreende a base etimológica da palavra "estereótipo".
} 
HALL, Stuart. Da diáspora: identidades e mediações culturais. Org. Liv Sovik. Trad. Adelaine La Guardia Resende et. al. Belo Horizonte: Editora UFMG, 2011.

PEREC, Georges. A viagem de inverno. In:

A coleção particular. Trad. Ivo Barroso. São Paulo: Cosac Naify, 2005. p. 73-82.

SANTIAGO, Silviano. Análise e interpretação. In: Uma literatura nos

trópicos: ensaios sobre dependência cultural. 2. ed. Rio de Janeiro: Rocco, 2000. p. 200-217.

. O entre-lugar do discurso latino-americano. In: Uma literatura nos

trópicos: ensaios sobre dependência cultural. 2. ed. Rio de Janeiro: Rocco, 2000. p. 09-26.

SELIGMANN-SILVA, Márcio. Globalização, tradução e memória. In: O local da

diferença: ensaios sobre memória, arte, literatura e tradução. São Paulo: Ed.34, 2005. p. 205-213.

\section{Title}

Cultural thresholds, attempts of interpret

\section{Abstract}

From Homi Bhabha's Third Space and Silviano Santiago's in-between place of Latin American discourse concepts, this paper aims to explore how the current arrangements of culture are related to interpretative propositions. And taking into account this relationship, the purpose is to observe how the concept of "contemporary", defended by Giorgio Agamben, may contribute to a reflection on the cultural displacements by looking at the intermissions and dissociations.

\section{Keywords}

Third Space. In-between. Contemporary. Culture. Interpretation. 